\title{
Programa Intercultural e-Culturas e a manifestação das emoções interculturais na interação entre Ensino Superior e Educação Básica
}

\author{
Marlene Zwierewicz * \\ Antonio Pantoja Vallejo ** \\ Elcio Willemann ${ }^{* * *}$
}

\begin{abstract}
Resumo
Viver em sociedades cada vez mais digitalizadas e migratoriamente dinâmicas traz para o âmbito das emoções uma versatilidade geográfica e temporal inédita, definindo novos contornos para a convivência humana. Nesse cenário, as emoções interculturais manifestam-se de forma diferenciada, estimulando a criação de alternativas educacionais que colaborem com seu manejo. Este artigo tem como objetivo sistematizar o Programa Intercultural eCulturas, uma iniciativa criada pelo Grupo de Pesquisa e Desenvolvimento Educativo da Orientação - IDEO - HUM 660, que pertencente ao Departamento de Pedagogia da Universidade de Jaén - UJA (Espanha). Organizado para estimular a interação entre estudantes do sétimo ano do Ensino Fundamental, visando a valorização da diversidade étnico-cultural, o programa é dinamizado a partir da interação entre Ensino Superior e Educação Básica e já oportunizou o intercâmbio entre estudantes de diversos países, como Argentina, Brasil, Chile, Espanha, Paraguai, Portugal e Reino Unido. Além de constituir-se em ação extensionista inédita, é também oportunidade para ressignificar o ensino e articular a pesquisa às demandas da realidade.

Palavras-chave: Emoções interculturais, Diversidade étnico-cultural, Ensino Superior, Educação Básica, Entornos Virtuais de Aprendizagem.
\end{abstract}

E-Culturas Intercultural Programme and the manifestation of cross-cultural emotions in the interaction between higher education and basic education

Abstract: to live in increasingly digitized and migratorily dynamic societies brings an unprecedented geographical and temporal versatility, setting new forms for human coexistence. In this scenario, intercultural emotions manifest themselves in a differentiated manner, encouraging

\footnotetext{
Professora do Centro Universitário Barriga Verde - Unibave (Santa Catarina/Brasil). E-mail: marlenezwie@ unibave.net

** Professor da Universidade de Jaén - UJA (Jaén/Espanha) - E-mail: apantoja@ujaen.es

*** Professor do Centro Universitário Barriga Verde - Unibave (Santa Catarina/Brasil). E-mail: elcio@unibave.net
} 
the creation of educational alternatives to cooperate with their management. This article aims to systematize the e-Culturas Intercultural Programme, an initiative created by the Trend Research and Educational Development - IDEO - HUM 660, which belongs to the Department of Education of the University of Jaén - UJA (Spain). The program was organized to stimulate interaction between students in the seventh grade of primary school, aiming at the promotion of ethnocultural diversity, and it was developed from the interaction between higher education and basic education, and already provided exchange between students from different countries, such as Argentina, Brazil, Chile, Spain, Paraguay, Portugal and United Kingdom. Apart from being an unprecedented extension action, it is also an opportunity to reframe education and coordinate research with the demands of reality.

Keywords: Intercultural emotions, Ethnocultural diversity, Higher Education, Basic Education, Virtual Learning Environments.

Introdução

O uso crescente das Tecnologias de Informação e Comunicação - EVA vem provocando modificações em diálogos, planejamentos, tomada de decisões e estabelecendo, com isso, uma variedade de relações virtuais. Além disso, esse processo inovador reduz as fronteiras geográficas e altera as fronteiras temporais, pois a interação pode ocorrer entre diferentes pessoas e a qualquer tempo.

Essa interação entre diferentes culturas, portanto, já não exige a presença física característica dos movimentos migratórios dos séculos passados, condição mencionada por Del Arco (1998) ao afirmar que a interferência entre culturas já não requisita, necessariamente, a mobilidade espacial em função das possibilidades que oferecem os meios de comunicação a distância.

Diante dessas mudanças, surge a preocupação com o respeito à diversidade cultural, incluindo as reações emocionais manifestadas no contato entre pessoas conectadas virtualmente. São formas de falar, vestir, comer, pensar, estudar e outros comportamentos diferenciados pelas influências multiculturais que podem provocar reações adversas, comprometendo a capacidade de convivência entre os que se conectam virtualmente.

Tendo como situação mobilizadora as reações emocionais manifestadas a partir do contado com diferentes culturas em Entornos Virtuais de Aprendizagem - EVA, foi criado, pelo Grupo de Pesquisa e Desenvolvimento Educativo da Orientação - IDEO - HUM 660, que pertencente ao Departamento de Pedagogia da Universidade de Jaén - UJA (Jaén - Espanha), o Programa Intercultural e-Culturas. Organizado para estimular a interação entre estudantes do sétimo ano do Ensino Fundamental, o programa já oportunizou o intercâmbio entre 
estudantes de países como Argentina, Brasil, Chile, Espanha, Paraguai, Portugal e Reino Unido.

O objetivo deste artigo é apresentar o referido programa e sua forma de dinamização, por meio da apresentação de sua estrutura, das fases que o integram e das possibilidades que oferece para mobilizar, a partir da articulação entre Ensino Superior e Educação Básica, as competências interculturais dos que se conectam em EVA. Trata-se, portanto, de um relato que compreende a criação e oferta do programa e as possibilidades que ele oferece para desenvolver competências interculturais imprescindíveis em uma sociedade globalizada.

Emoções interculturais em Entornos Virtuais de Aprendizagem - EVA

Viver em sociedades cada vez mais digitalizadas e migratoriamente dinâmicas traz para o âmbito das emoções uma versatilidade geográfica e temporal inédita, definindo novos contornos para a convivência humana. Nesse cenário, Motta alerta que

O devenir humano na era planetária, distante de iluminar-se, está sendo cada vez mais sombreado. As nuvens de pólvora do século XX não se dissiparam, estando, ao contrário, mais enegrecidas que em outros tempos, pulverizando as boas expectativas em relação ao século iniciado [...]. (2015, p. 3)

É nesse contexto que a intenção de explorar os EVA como espaços para estimular o manejo das emoções interculturais é justificada. Essas emoções integram dois conceitos: emoção e cultura. Quanto ao primeiro, parte-se do princípio de que a consciência sobre si e sobre o outro e a consciência acerca do mundo exterior constroem-se na relação que a pessoa estabelece com o mundo e com os outros. Nesse processo, a emoção transforma-se em um meio de expressão que abre caminho para a linguagem (CAMARGO, 1999). Em se tratando de cultura, reitera-se as considerações de Del Arco (1998), que destaca sua característica mutante, mas capaz de articular opiniões de um grupo social, selecionadas para possibilitar a sobrevivência. Nesse sentido, Barreiros e Morgado (2002) ressaltam a importância de definir cultura como um processo social, como algo produzido, sendo uma instância na qual a comunicação exerce uma função fundamental para que cada grupo organize sua identidade. São essas perspectivas que influenciaram o surgimento da expressão emoções interculturais, cunhada por Zwierewicz (2012).

As emoções interculturais são consideradas reações emocionais manifes- 
tadas a partir das relações multiculturais. Elas predispõem a pessoa a uma resposta que pode ser compreensiva desde que os existam condições para tanto, especialmente quanto à formação, já que as mudanças das últimas décadas têm sido intensas e repercutem em necessidades formativas cada vez mais sistemáticas. (ZWIEREWICZ, 2012, p. 192)

Além de se manifestarem presencialmente, as emoções interculturais também se expressam virtualmente, condição implicada na conexão entre diferentes culturas que podem apresentar características próximas ou distantes dos sujeitos conectados. Para explorar com equilíbrio os extraordinários mosaicos multiculturais que se formam, cada pessoa necessita manejar suas emoções, evitando decisões que gerem discriminação e dificultem um percurso respeitoso e solidário. Zwierewicz (2012) lembra que, nesse processo, pode ocorrer tanto a imposição de uma cultura sobre a outra como uma comunicação compreensiva que promove a expressão de atitudes solidárias, colaborando para o direito de ser, pensar e agir de forma distinta ou similar.

Ao defender que é necessário dotar as pessoas de valores, competências e atitudes para atuar em sociedades cada vez mais multiculturais, Zwierewicz (2012) recorre a Del Arco (1998), defensora da necessidade de criar alternativas de intervenção educativa que favoreçam a coexistência e evitem aos coletivos excluídos a assimilação da cultura predominante. Nesse sentido, Del Arco evidencia a necessidade de uma comunicação compreensiva por meio da qual ambas as partes "[...] se reconheçam como diversas entre si, desembocando e um enriquecimento mútuo, uma valorização e um reconhecimento." (1998, p. 39).

Já Dourado e Prandini (2001) recorrem a Wallon (1975) para situar fatores fundamentais nesse processo. São elas: condições necessárias para que a capacidade humana se manifeste, a importância do contato com a cultura e o desenvolvimento de capacidades, o papel da escola no desenvolvimento de capacidades. Portanto, uma capacidade se manifesta quando existem esses fatores implicados.

As reflexões de Wallon (1975) contribuem para posicionar o papel das instituições educativas, no desenvolvimento das emoções, como facilitadoras do acesso a culturas diversas, colaborando para compreensões e vivências que valorizem o que está para além do entorno. Faz-se pertinente também que todos os estudantes recebam oportunidades traçadas de acordo com suas características, para que cada um possa desenvolver-se segundo suas especificidades.

Os recursos tecnológicos podem exercer um papel determinante no desenvolvimento de novas capacidades. Para tanto, as instituições de ensino necessitam redimensionar práticas pedagógicas centradas no desenvolvimento cognitivo, que subesti- 
mam a dimensão emocional e a necessidade de trabalhar com valores humanos como a liberdade, a convivência, a solidariedade e a colaboração (Zwierewicz, 2009). Nesse sentido, Torre (2009) valoriza a escola como um campo aberto, uma instituição que aprende, que se transforma e dinamiza culturas.

Tendo como bases as reais condições tecnológicas, a dinamização multicultural e a relevância das instituições de ensino para trabalhar as emoções, a proposição de programas com foco nas emoções interculturais tem aqui como exemplo o Programa Intercultural e-Culturas, que considera as especificidades dos estudantes e, no caso, os envolvidos têm faixa etária entre 11 a 12 anos de idade. Para Wallon (1975), essa fase corresponde a uma transição da etapa categorial (expressão usada pelo autor) à adolescência, sendo comum a manifestação das seguintes características nos estudantes:

- são capazes de participar de várias equipes de forma diferenciada e segundo a atividade em desenvolvimento;

- desenvolvem uma consciência acerca da equipe e sobre si em relação a outras pessoas;

- enfrentam transformações de ordem fisiológica e corporal, impostas por uma maturação sexual e de ordem psíquica com preponderância efetiva;

- enfrentam sentimentos que se alteram ao buscar a consciência de si mesmos na figura do outro;

- são influenciados pelo meio sociocultural, sendo que parte rejeita padrões de conduta familiares, identificando-se mais com o perfil de grupos externos;

- passam por momentos em que se torna mais visível a influência do meio como condicionante da existência, configurando personalidades de forma distinta, pois enquanto parte pertence a situações socioeconômicas mais favoráveis, outros vivenciam a etapa enfrentando, muitas vezes, precocemente a realidade de um adulto, especialmente quando necessitam contribuir para a subsistência familiar.

Além dessas mudanças, os estudantes com a idade indicada sofrem as influências das tecnologias e dos movimentos migratórios, estando expostos a uma carga significativa de fatores que interferem em seu desenvolvimento. Assim, o Grupo IDEO considerou essa uma idade oportuna para a oferta do Programa Intercultural e-Culturas e adotou uma estrutura que converge com tal perfil, corroborando com Bisquerra (2007) quando o autor afirma que: 
- todos os estudantes devem ter oportunidades iguais, incluindo o respeito à sua singularidade;

- deve haver uma escola para todos e um contexto onde cada um possa desenvolver-se de acordo com suas potencialidades;

- devem ser cultivados valores de solidariedade e justiça;

- os docentes precisam conhecer as condições de existência dos estudantes, para que os valores vinculados ao bem-comum sejam estimulados.

Permeado por essas reflexões, o Programa Intercultural e-Culturas dinamiza uma interação que ultrapassa a fronteira de sua origem para proporcionar aos estudantes de diferentes países uma oportunidade inédita para a potencialização de culturas locais e valorização de culturas globais. As circunstâncias de sua criação, seus objetivos e sua operacionalização são apresentados a seguir, detalhando, assim, as fases que o compõem e a forma com que os estudantes aprofundam o autoconhecimento e o conhecimento das culturas daqueles com quem interagem.

\section{Criação, objetivos e operacionalização do Programa Intercultural e-Culturas}

O Programa Intercultural e-Culturas foi criado no ano de 2005. Naquela época, o Grupo de Pesquisa IDEO, responsável por sua criação e oferta, considerou em sua estruturação as reflexões de Aguado (2003) ao afirmar que a chave para o êxito do uso da Web com enfoque intercultural reside na estrutura apropriada de entornos de educação em linha. Nesse sentido, o compromisso do IDEO, ao disponibilizar o programa no sítio http://www.e-culturas.org, foi de: organizar uma plataforma personalizada; favorecer a interação entre centros, disciplinas e docentes; criar materiais interativos.

Pantoja e Villanueva (2015) indicam que são os objetivos do programa desenvolver estratégias e habilidades cognitivas (análise, síntese, representação, elaboração, criatividade etc.) para o desenvolvimento intercultural; melhorar o conhecimento sobre si mesmo; estimular atividades cidadãs frente aos processos migratórios, considerando valores democráticos vinculados aos estudantes e a realidade das instituições envolvidas. Para isso, o programa compromete-se com o desenvolvimento da identidade étnica-cultural dos estudantes, o respeito ao pluralismo cultural, a educação para a cidadania, a reflexão e análise crítica da pessoa, o reconhecimento da identidade ética-cultural da pessoa, para chegar-se ao outro e colocar-se no lugar dele, o respeito à diversidade, a elevação da autoestima e do autoconceito, a compreensão do conceito 
de cultura como algo dinâmico, a incorporação desses valores no contexto rotineiro da sala de aula (PANTOJA; BLANCO, 2011).

Para possibilitar a oferta do programa, foi criada a Red Internacional e-Culturas, formada por Argentina, Brasil, Chile, Espanha, Paraguai, Portugal e Reino Unido. Nas distintas edições do programa, foram incorporadas melhoras discutidas na referida rede (PANTOJA; VILLANUEVA, 2015).

A Figura 1 caracteriza o processo de operacionalização do programa. A etapa inicial consiste na assinatura de um convênio entre a universidade interessada e a Universidade de Jaén. Esse processo legitima a oferta do programa pela universidade interessada às escolas públicas e privadas.

Figura 1 - Organograma de operacionalização do e-Culturas

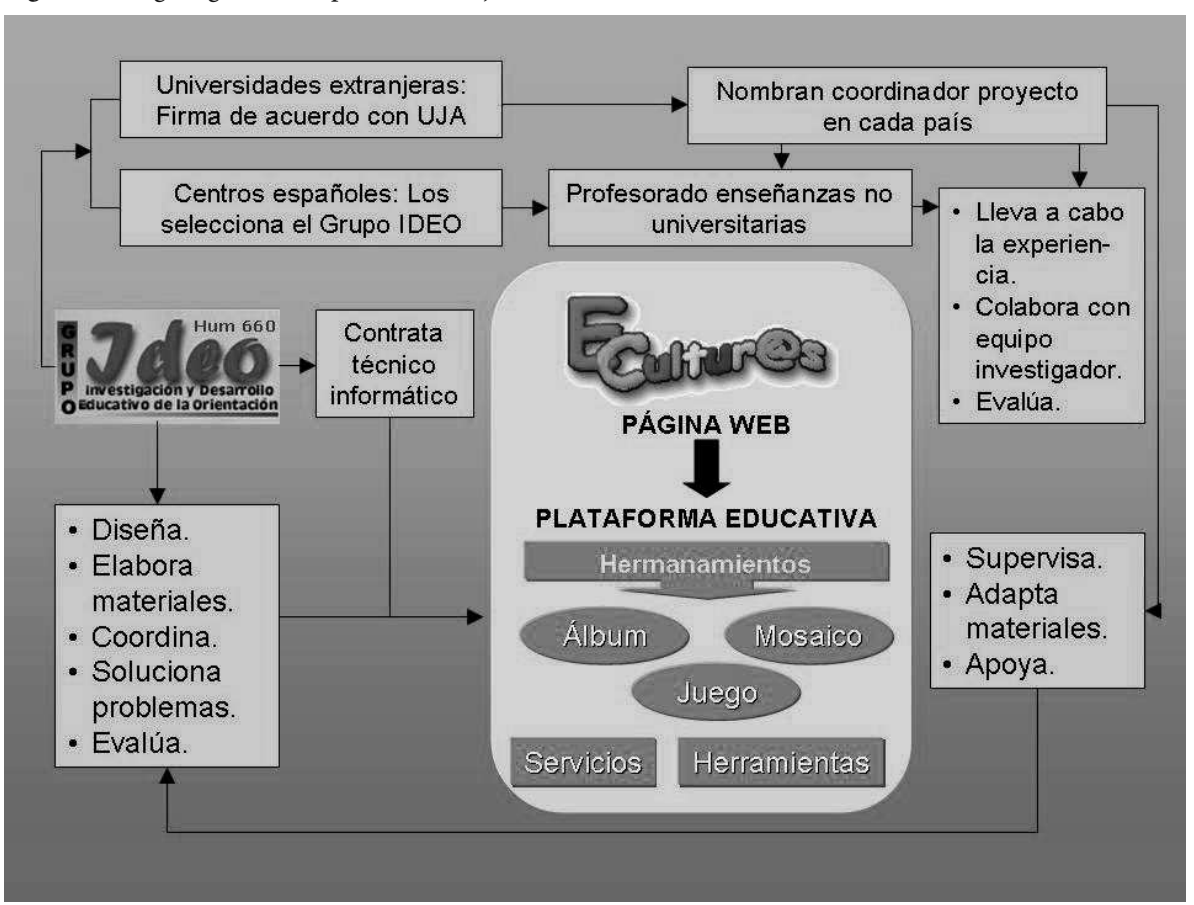

Fonte: Pantoja et al (2006)

A primeira experiência com o e-Culturas foi realizada em 2005, a partir de um convênio entre a Universidade de Jaén - UJAe a Escola Superior Politécnica do Litoral 
de Guayaquil, Equador. Essa primeira experiência contribuiu para desencadear um processo que perdurou nos anos subsequentes, facilitando identificar potencialidades e fragilidades do programa.

A partir de 2006, o programa foi incorporado por outras Instituições de Ensino Superior. Uma delas é o Centro Universitário Barriga Verde - Unibave, que tem se responsabilizado pela oferta de todas as edições do programa desenvolvidas de 2006 a 2016. A inserção do contexto brasileiro no programa está vinculada à pesquisa que resultou na tese Desarrollo de emociones interculturales en Entornos Virtuales de Aprendizaje - EVA (2012), desenvolvida por Zwierewicz.

A página que torna o programa acessível (http://www.e-culturas.org) oferece possibilidades de interatividade vinculadas às atividades desenvolvidas nas três fases disponibilizados na estrutura do programa, que são apresentadas adiante, além de ferramentas adicionais (vocabulário intercultural configurável, fóruns, blog, entre outras) para a interação entre estudantes, docentes e gestores participantes, como pode ser observado na Figura 2.

Figura 2 - Ferramentas de interação do Programa Intercultural e-Culturas

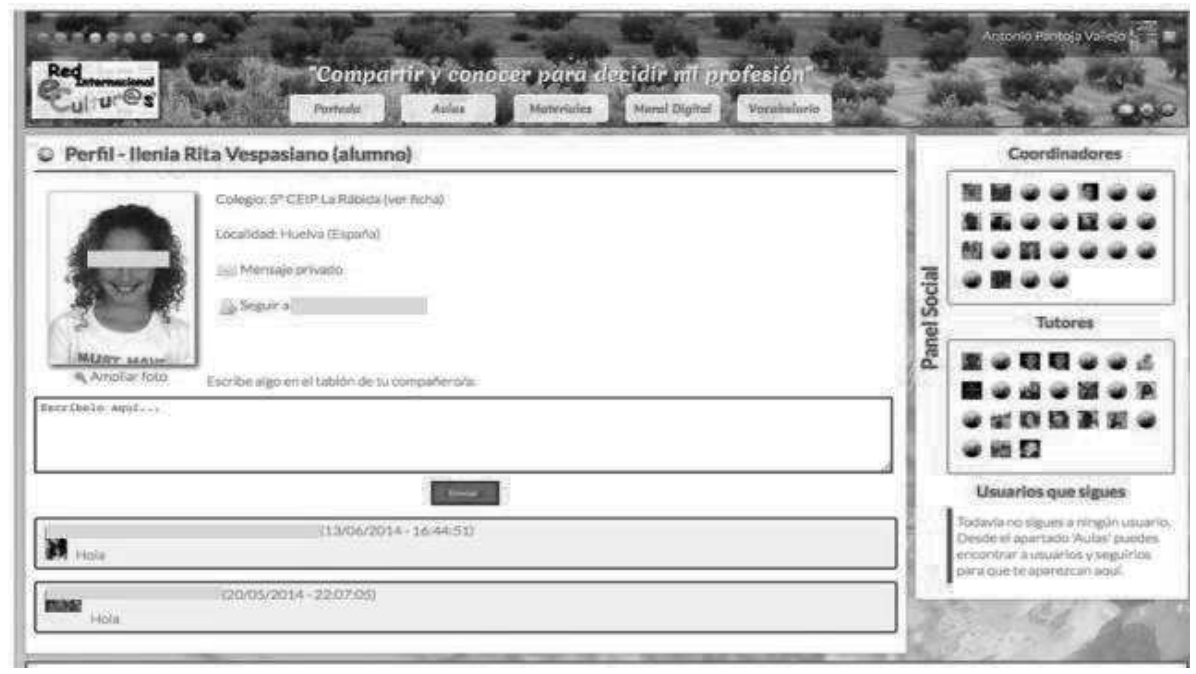

Fonte: http://www.e-culturas.org 
Pantoja e Villanueva (2015) destacam que a característica temática do Programa possibilita aos estudantes o desenvolvimento de atividades e a exploração dos recursos existentes. Para esses autores, a comunicação entre eles e os centros vinculados é um dos potenciais do programa, por isso, além da interação contínua entre pequenas equipes, também é estimulada a realização de videoconferências, que ampliam o diálogo entre as turmas completas de estudantes de diferentes países durante o desenvolvimento da proposta.

\section{Fases do Programa Intercultural e-Culturas}

A estrutura central do Programa Intercultural e-Culturas é constituída por três fases que oferecem possibilidades para o trabalho individual e colaborativo, envolvendo conteúdos derivados de diferentes áreas do conhecimento. Assim, existe uma preocupação da Rede Internacional e-Culturas de que os estudantes possam articular os conteúdos previstos no programa com os conteúdos curriculares, sem desconsiderar, nesse processo, as demandas dos diferentes contextos que participam da proposta.

Fase 1: o lugar onde vivo

Essa fase favorece o autoconhecimento e o conhecimento do outro e do entorno em que se inserem as equipes que trabalham colaborativamente. Seus objetivos são:

- familiarizar o estudante com o sistema de informática;

- estabelecer contato com os estudantes de outras culturas;

- reconhecer a própria identidade a partir do confronto com a identidade do outro;

- tomar consciência da identidade dos demais;

- conhecer como são e como vivem os companheiros 'hermanados'.

O formato da fase, configurando um álbum, possibilita a postagem de imagens e textos, conforme pode ser observado na Figura 3. Em seu desenvolvimento, os estudantes são divididos em equipes e participam de uma sequência didática que envolve o próprio estudante, sua família, seus amigos, sua escola e suas tradições culturais. 
Figura 3 - Atividade vinculada à Fase 1 do Programa Intercultural e-Culturas

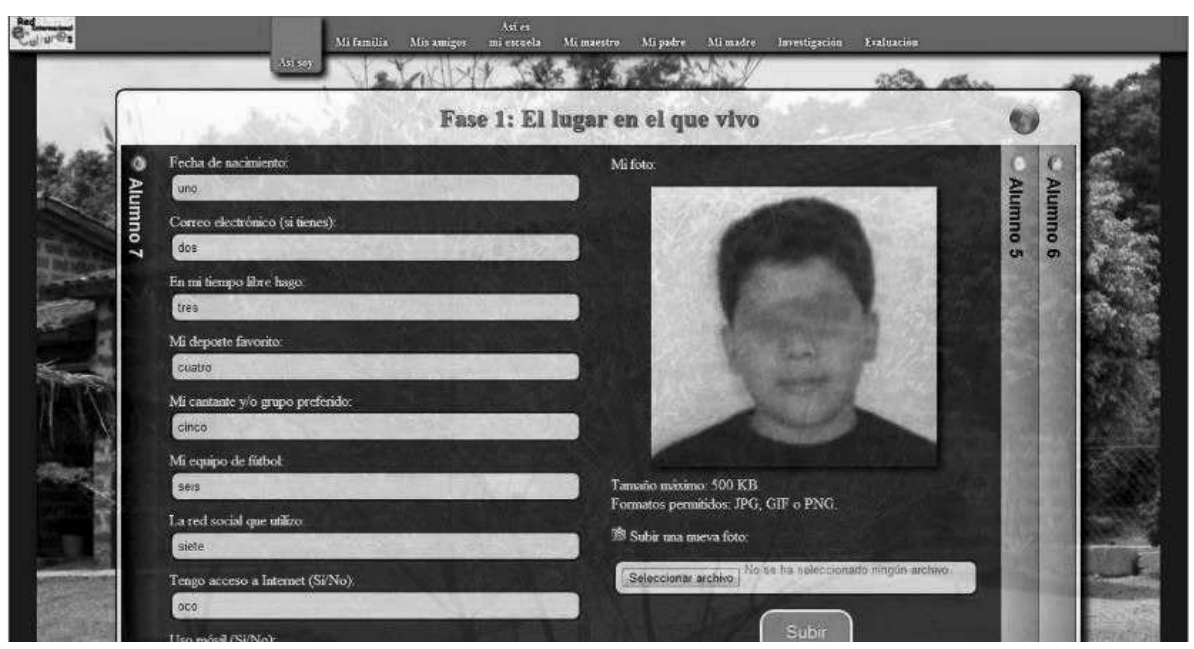

Fonte: http://www.e-culturas.org

Os tópicos que compõem a sequência didática são: eu sou, minha família, meus amigos, meu professor, minha mãe, meu pai. Além disso, a fase prevê uma pesquisa sobre um aspecto da cultura local e a avaliação das atividades desenvolvidas.

Para estimular o autoconhecimento e o conhecimento da realidade do outro, a fase oferece possiblidades para o diálogo, por meio de ferramentas de bate-papo, além das ofertadas em espaços que ultrapassam as atividades.

\section{Fase II: o que quero ser quando crescer? Conheça as diferentes profissões}

A segunda fase estimula o conhecimento acerca das diferentes profissões, promovendo a aproximação do estudante com especificidades do mundo do trabalho ao transitar por diferentes profissões organizadas a partir de áreas próximas de atuação organizadas em grupos como: científico-sanitário, científico-técnico, científico-experimental, humanista-literário, psicopedagógico-social-político, artes, música, esportes, segurança-defesa, econômico-empresarial, administrativo-persuasivo-comercial, agropecuário, mecânico-manual, aventura-risco. 
Figura 4 - Atividade vinculada à Fase 2 do Programa Intercultural e-Culturas

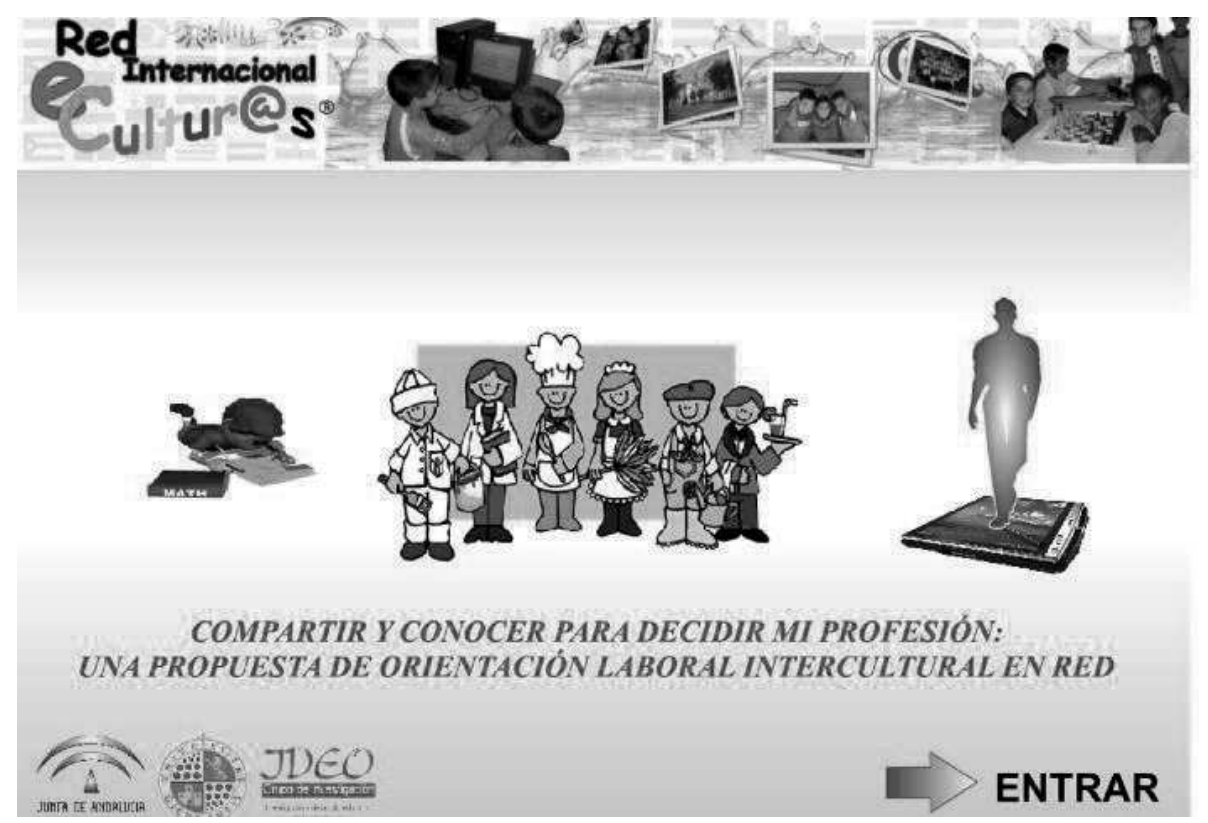

Fonte: http://www.e-culturas.org

São objetivos da fase, entre outros: intercambiar informação sobre as diferentes profissões do mundo; realizar um processo de orientação laboral ajustada às necessidades, potencialidades e realidades do mercado de trabalho; realizar projetos colaborativos. Em seu desenvolvimento, os estudantes trabalham em equipes formadas por área de interesse. 
Figura 5 - Atividade vinculada à Fase 2 do Programa Intercultural e-Culturas

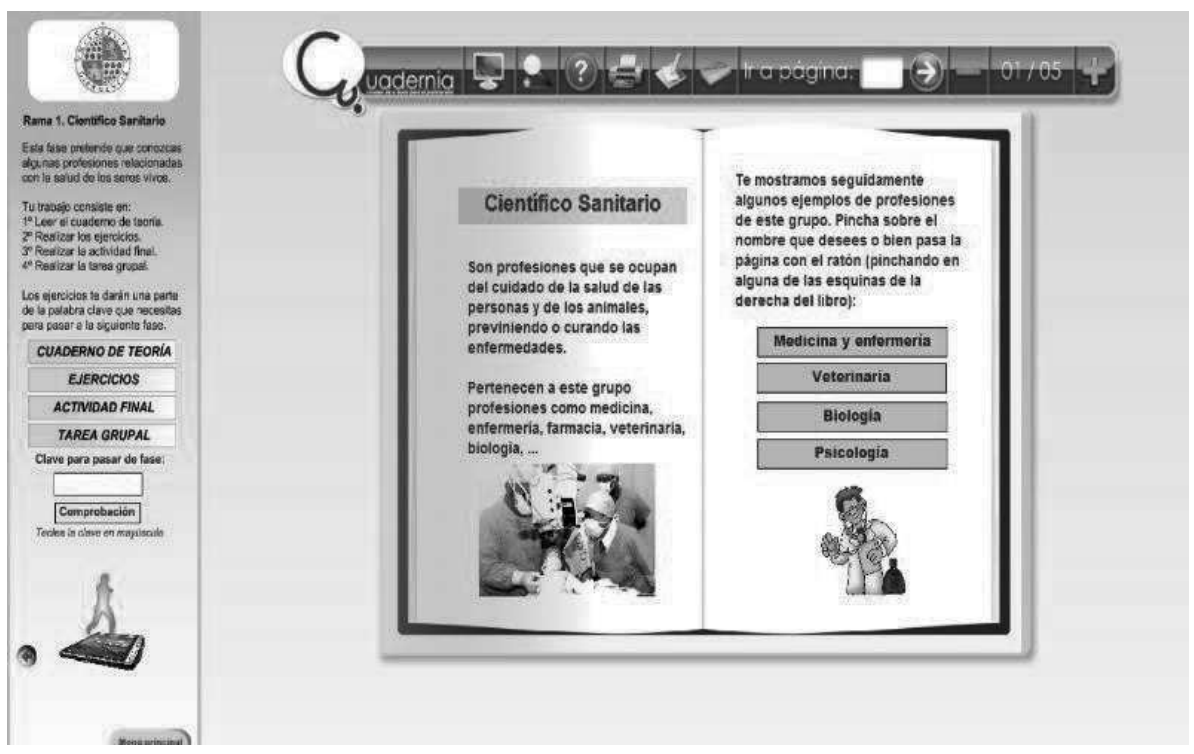

Fonte: http://www.e-culturas.org

As atividades que integram essa fase são formadas por jogos virtuais, trocas de informações, pesquisas envolvendo bases de dados e a realidade local, bem como a elaboração de projetos compreendendo a área selecionada. Dessa forma, estimulam o conhecimento da realidade local e global, destacando profissões em ascensão e decadência.

\section{Fase III: ‘Quijotín’ e o mundo do trabalho}

A terceira e última fase consiste na participação dos estudantes em um jogo desenvolvido a partir de pesquisas que envolvem a cultura de forma geral e questões específicas de Geografia, História, línguas e outros aspectos da realidade de cada país participante do programa. Seus objetivos são: estimular a consciência acerca da existência de uma cultura comum e observar questões relacionadas à identidade individual e à identidade coletiva. 
Figura 6 - Atividade vinculada à Fase 3 do Programa Intercultural e-Culturas

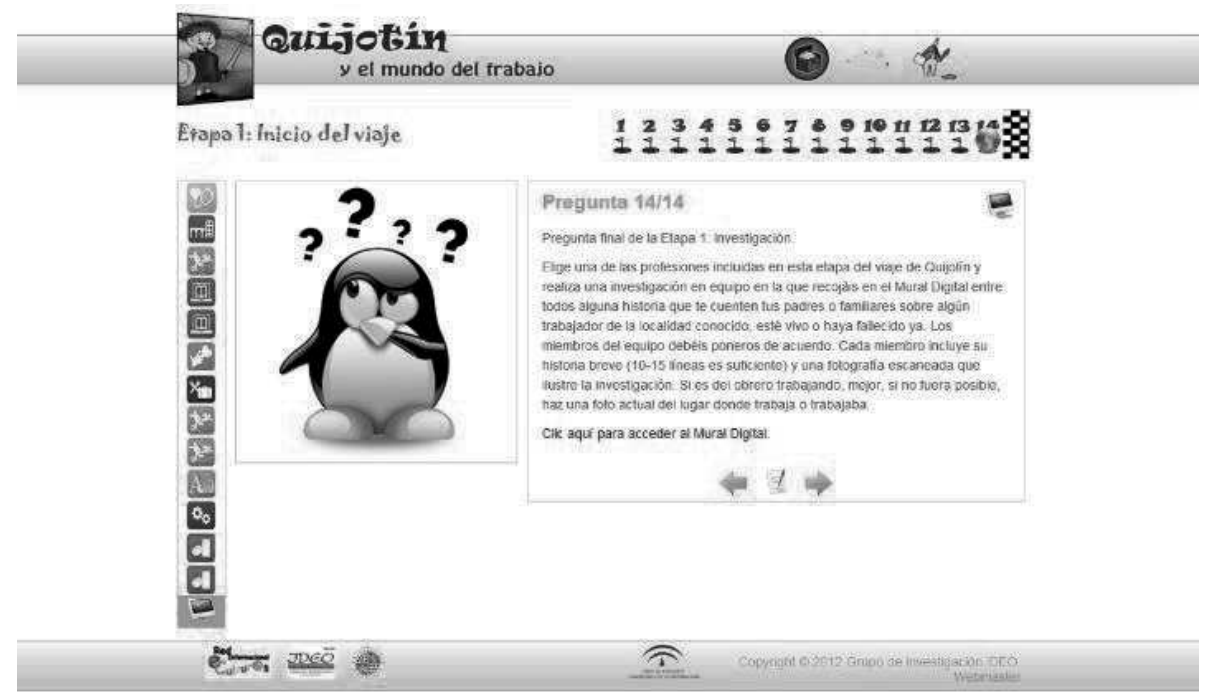

Fonte: http://www.e-culturas.org

O personagem Quijotín - suposto filho do Dom Quixote - foi idealizado pelo Grupo IDEO para ser o mascote da fase. No início do jogo, ele sai da Universidade de Jaén em seu cavalo e começa um percurso transitando pela Espanha até finalmente chegar ao último país. No percurso, levanta uma série de questionamentos que precisam ser pesquisados pelos estudantes para poder dar sequência ao jogo.

\section{Considerações finais}

A ampliação no uso das TIC provoca mudanças nos relacionamentos entre as pessoas, expondo-as a situações permeadas por sociedades cada vez mais digitalizadas e migratoriamente dinâmicas. Assim, compete aos sistemas educacionais a promoção de alternativas que colaborem para o manejo das emoções interculturais.

A oferta do Programa Intercultural e-Culturas e sua dinamização em diferentes países têm possibilitado a estudantes do Ensino Fundamental a oportunidade de aprofundarem o conhecimento sobre sua própria realidade e o diálogo com culturas diferenciadas. No seu desenvolvimento, as três fases provocam os estudantes a valori- 
zar a sua realidade e a realidade dos outros, favorecendo a manifestação de emoções que superam a rejeição e a discriminação.

Ao postar imagens e informações na primeira fase, os estudantes podem observar características que os distanciam ou aproximam dos demais conectados. Nesse sentido, têm a oportunidade de ressignificar estereótipos e perceber que, mesmo distantes, muitos se movem por valores comuns.

Ao transitar por diferentes profissões, trabalhando colaborativamente, ampliam os horizontes formativos para analisar a realidade profissional. Desse modo, aprofundam conhecimentos acerca da área de interesse e observam a dinamicidade da profissão no contexto local e em outras realidades, nacionais ou internacionais.

Ao pesquisar possíveis respostas para os questionamentos da terceira fase, possibilita-se aos estudantes a articulação entre aquilo que rotineiramente aprendem na sala de aula com conceitos e conteúdos explorados pelo programa. Isso proporciona mais sentido ao trabalho escolar, pois eles percebem as implicações dos conteúdos na realidade que os cerca e na realidade dos demais estudantes que participam do programa.

Essas possibilidades oferecem oportunidades inéditas para o diálogo com o outro e para avaliar as reações emocionais que se manifestam no contato com o que se aproxima ou se distancia da realidade. É nesse processo que o programa estimula o manejo das emoções interculturais que se manifestam na interação virtual.

Além dessas possibilidades que envolvem o respeito à diversidade étnico-cultural e o manejo das emoções interculturais, acentua-se que o programa é uma alternativa para dinamizar o estudo de conteúdos de diferentes áreas do conhecimento, favorecendo, entre outros aspectos, o interesse pela língua estrangeira. Sendo uma ferramenta de inclusão digital, seu formato educativo traz para o contexto escolar de diferentes países uma alternativa inédita de interação e colaboração. Quiçá seja também uma alternativa para suavizar as nuvens de incertezas que pairam nos diferentes contextos do planeta e colabore para consolidar as boas expectativas que se tinha em relação ao século XXI, anunciadas por Motta (2015), e que envolvem a realidade cultural, ambiental, econômica, social e política.

\section{Referências}

AGUADO, T. Pedagogía intercultural. Madrid: McGraw-Hill, 2003.

BARREIROS, D.; MORGADO, V. Multiculturalismo e o campo do currículo no Brasil: 
um estudo sobre multieducação. In: OLIVERIA, I. B.; GARBI, P. (Orgs.). Redes culturais: diversidade e educação. io de Janerio: DP\&A, 2002. p. 93-108.

BISQUERRA, R. Educación emocional para la convivencia. Murcia: Universidade de Murcia, 2007. Disponível em: <http://jornadasconvivenciamurcia.com/ponencias/ bisquerra_alsina_rafael-educacion_emocional_para_la_convivencia.pdf $>$. Acesso em 20 maio 2015.

CAMARGO, D. Emoção, primeira forma de comunicação. Interação, v. 3, Curitiba, v. 3, p. 09-20, jan./dez. 1999. p. 9-20.

DEL ARCO, I. Hacia una escuela intercultural: El profesorado, formación y expectativas. Lleida: Ediciones Universitat de Lleida, 1998.

DOURADO, I. C. P.; PRANDINI, R. C. A. R. (2001). Henri Wallon: Psicologia e Educação. In: XXIV Reunião Anual da Associação Nacional de Pós-Graduação e Pesquisa em Educação (ANPED). Caxambu. Disponível em: <http://www.anped.org.br/reunioes/24/tp1.htm\#gt20>. Acesso em: 20 jun. 2015.

MOTTA, R. Editorial. Complejidad. n. 28, out./dez. 2015. p. 3-6.

PANTOJA, A. Acción tutorial y nuevas tecnologías. In: Álvarez, M. (Dir.) La acción tutorial: su concepción y su práctica. Madrid: MEC, 2006. p. 219-261.

PANTOJA, A.; VILLANUEVA, C. Mejoras del conocimiento de la cultura propia y del otro tras la aplicación de un programa basado en las TIC. Revista de Investigación Educativa, n. 33, v. 1, 2015. p. 133-148.

PANTOJA, A.; BLANCO, E. Aprendizaje colaborativo y heurístico en la red e-Culturas. Teoría de la Educación: Educación y Cultura en la Sociedad de la Información, n. 12, v. 4, 2011. p. 39-52.

TORRE, S. Escolas Criativas: Escolas que aprendem, criam e inovam. In: ZWIEREWICZ, Marlene; TORRE, Saturnino de la (Org.). Uma escola para o século XXI: escolas criativas e resiliência na educação. Florianópolis: Insular, 2009. p. 55-70. 
WALLON, H. Psicologia e educação da infância. Lisboa: Estampa, 1975.

ZWIEREWICZ, M. Desarrollo de emociones interculturales en Entornos Virtuales de Aprendizaje (EVA). 2012. 475 p. Tese de Doutorado em Educação (Doutorado em Educação). Universidade de Jaén - UJA. Jaén, 2012.

ZWIEREWICZ, M. Trabajar con emoción y valores para fortalecer la resiliencia en la escuela. In: TORRE, S.; PUJOL, M. A. (Org.) Educar con otra conciencia: una mirada ecoformadora y creativa de la enseñanza. Barcelona: Davinci Continental, 2009. p. 129-138.

Recebido em: 10 abril 2016.

Aceito em: 21 abril 2016. 